\title{
Naturaleza Muerta. Psicotanatología Forense
}

\author{
Damián G. Ricardo *
}

\section{Resumen}

Lo tanático aparece a partir de la lectura psicoanalítica como un accionar silencioso, acallando el ruido de unión de Eros. La naturaleza muerta nos muestra un momento de ese equilibrio dinámico: al mismo tiempo que la vida resiste, todo se muere por causas internas (Freud, 1938/1976).

La Psicotanatología Forense se propone como un conjunto disciplinar que involucra una serie de dispositivos que permiten aportar desde la psicología elementos necesarios para incorporar a la investigación judicial.

Este breve texto se propone un diálogo estético con las bases epistemológicas de la psicotanatología forense, que permite abordar algunos conceptos del campo de la estética y la ciencia para definir el campo de estudio que toma como eje central la investigación de la muerte violenta en el ámbito judicial.

La naturaleza muerta expresa en la pintura la frase memento mori, y con ello el detenimiento del instante y la apreciación en todas sus complejas dimensiones. Acontecimiento efímero e infinito, como la muerte.

Palabras clave: $\quad$ Psicotanatología forense - Psicología forense - Tanatología Naturaleza muerta 


\title{
Still life. Forensic Psychotanatology
}

\author{
Damián G. Ricardo *
}

\begin{abstract}
The tanatic appears from the psychoanalytic reading as a silent action, quieting the union noise of Eros. Still life shows us a moment of this dynamic balance: at the same time that life resists, everything dies from internal causes (Freud, 1938/1976).

Forensic Psychotanatology is proposed as a disciplinary set that involves a series of knowledge that allows you to provide the necessary elements from psychology to incorporate into the judicial investigation.

This project shows the epistemological bases to unify in this field of knowing the investigations that gather psychological expertise in cases of violent deaths.

Still life expresses the phrase memento mori in painting, and with it the pause of the moment and appreciation in all its complex dimensions. Ephemeral and infinite event.
\end{abstract}

Keywords: Forensic Psychotanatology - Forensic Psychology - Thanatology Still life 


\section{Tánatos}

Tánatos (Oávatos Thánatos) es la personificación de la muerte no violenta. Con toque suave como su hermano Hipnos, el sueño. Pero también era hermano del destino (Moiras), la condenación (Moros), la discordia (Eris), la vejez (Geras), la venganza (Nemesis), el barquero (Caronte), y otras personificaciones. Pero la muerte violenta era dominio de sus dos hermanas: las Kéres, (MARCH, J., CASSELL'S, 1999).

Si bien las Kéres sobrevolaban los campos de batalla en busca de heridos y enfermos, la extensión hace significación a plaga o enfermedad, кńpعৎ Өavátoı. El verbo

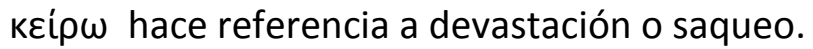

Del espectro de personificaciones, la denominación de Tánatos es la que representa en general la muerte, y en términos psicoanalíticos, el sentido amplio de su utilización comprende aquellas acciones violentas que atentan contra la vida.

La tanatología es una disciplina que se encarga de los procesos relacionados con la

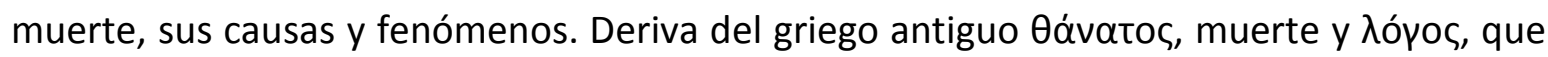
entre sus acepciones puede resultar discurso o estudio. Es una rama de la medicina legal que se encarga del estudio del cadáver y sus cambios a lo largo del tiempo. Su producción científica se extiende desde los aspectos biológicos hasta los interdisciplinarios, psicológicos y sociales.

La tanatología forense es el estudio del cuerpo después de la muerte. El camino hacia su desintegración del cuerpo vivo.

Cromática: cambio de color en función de la putrefacción de las proteínas.

Enfisematosa: la invasión de bacterias que invaden el cadáver y las sustancias que se forman en este proceso.

Período licuefactivo o licuefacción: desintegración de las vísceras.

Reducción: el proceso por el que la osamenta se transforma en polvo.

Como podemos observar este camino de desintegración comprende una serie de análisis en las que los aspectos vitales cesan y se ponen en marcha una serie de cambios físicos y químicos que ocurren hacia la reintegración completa de los restos al medio. El cuerpo va integrándose al medio por una serie de desagregados, que el impulso vital mantenía regulado bajo la lógica de lo viviente.

Así como lo viviente surge como separación de un medio físico al cual pertenece pero del cual se individúa, la desintegración es la vuelta al medio lo que antes permanecía individuado (Simondon, 2015).

La tanatología forense, entonces, estudia este proceso para establecer las condiciones en las que un resto viviente se encuentra en un proceso material de desagregación de sus compuestos o de metamorfosis en cierta manera regrediente. En el proceso de individualización física propuesta en la metafísica de Gilbert Simondon el individuo surge como una relación de asimetría entre una continuidad del medio y una discontinuidad en el devenir de su surgimiento. Desde la introducción del campo cuántico que introduce Simondon establece una discontinuidad en términos energéticos, en una 
continuidad en términos estructurales, estableciendo una teoría de los umbrales de transformación que admiten "saltos bruscos" (quantum energético) estableciendo una pareja individuo-campo desde su constitución y una evolución no lineal (Tula Molina, 2014).

En este proceso de individuación física los individuos se constituyen como singularidades totalizantes con una cualidad estructural que constituye su forma, que determina sus cualidades topológicas, y una cualidad de sistema, que determina las condiciones de su energía: "la individuación [...] no puede existir sin una discontinuidad elemental a escala más restringida" (Simondon, 2015, p. 135). Este autor refiere que lo discontinuo desordenado equivale a lo continuo, es funcionalmente continuo, pero lo continuo no puede manifestarse discontinuo porque es isotrópico. La materia es al mismo tiempo continua y discontinua. La discontinuidad se observa en diversos cuerpos aislados que forman estructuras, pero es continua toda vez que los cuerpos sueltos conforman cierta integridad. En este sentido la discontinuidad es primera en relación a lo continuo siendo que el estudio de la individuación exige lo discontinuo del germen estructural y lo continuo funcional del medio amorfo previo (p. 137).

La individuación parte entonces de las condiciones previas que permiten las condiciones de formación de ese individuo. Es una operación de estructuración amplificante que hace pasar a nivel macroscópico las propiedades activas de la discontinuidad primitivamente microfísica. Las condiciones hilemórficas (forma y materia) se transforman en condiciones metaestables estableciendo la singularidad (información) como aquella comunicación que existe entre ordenes de magnitud. Es decir que el individuo emerge como una condición de singularidad en ese medio que contenía el germen de su surgimiento bajo la forma de entidades preindividuales que se encontraban anteriormente. El proceso de reintegración a un estado inanimado supone el camino regrediente hacia ese estado previo, anterior al surgimiento de esa estructura metaestable subjetiva.

Desde que surgimos como singularidad en la existencia, lo hacemos a partir de esas condiciones singulares que permiten la existencia de una forma subjetiva metaestable que sostienen los cambios a través del tiempo y que conlleva una serie de individuaciones físicas, biológicas, psicológicas y sociales. Cada uno de estos procesos de individuación genera nuevas formas de estructuración metaestables que dejan huellas y marcas en el entorno.

La muerte como estudio de la tanatología forense, se establece en la ruptura definitiva de esta metaestabilidad estableciendo lo viviente y lo no viviente en cierto nivel dimensional. Por debajo de la física pura se encuentran las magnitudes inferiores que son prefísicas y previtales. La física pura comienza en un nivel supramolecular que aún es no viviente. Las formas macrofísicas de individuación distinguen lo viviente de lo no viviente, cuestión que no parece ser evidente en el proceso de individuación, donde el animal requiere la forma más simple vegetal, de la que lleva información consigo, de la misma manera en que el vegetal requiere los compuestos químicos para su supervivencia. 
Pero aún existe un nivel superior de individuación que el físico-orgánico, el psicológico. Este campo es tenso y rico en virtualidades. Incluye tanto la relación sujetomundo, como sus conflictos internos. Está tensado de modo profundo por la polaridad placer-dolor; pero también incluye la sensación polarizada en luz-claridad, y la afección polarizada en estados alegres y tristes (Simondon, p. 381). De esta manera surge una resonancia interna que condiciona lo interno y lo externo en un intercambio de información y causalidad. Este proceso se inicia con la ruptura de la díada materna hasta el encuentro con el Otro. Hay otro imaginario, opuesto al Otro simbólico (de la ley, del orden), ese otro es el de la propia imagen exterior, es donde el yo se apoya y rivaliza al mismo tiempo "La irrealidad imaginaria (de la ruptura), aunque fuera impostura, pertenece a la realidad de un espectro complejo de la capacidad humana" (Hoezen Polack, 2002 , p. 9). Es a partir de este campo de subjetivación, esta nueva individuación, al igual que las demás, genera efectos de estructura y el anudamiento singular de los registros de ese sujeto, el cuerpo muerto.

¿Todo acontecimiento es de este tipo, bosque, batalla y herida, tanto más profundo cuanto que ello que ocurre en la superficie, incorporal a fuerza de extenderse a lo largo de los cuerpos? La historia nos enseña que las buenas rutas no tienen fundación y la geografía, que la tierra no es fértil sino en una delgada capa (Deleuze, 1970, p. 13).

\section{Naturaleza muerta}

El bodegón de cazas, hortalizas y frutas constituye una obra maestra del pintor Juan Sánchez Cotán en el año 1.602. El instante de lo cotidiano, con un realismo perfeccionista pero sobrio, nos brinda una imagen íntima, que es al mismo tiempo cálida y ominosa. En un marco dispone los elementos que son reproducidos de una forma magistral, un naturalismo que ha sido intervenido por la acción humana: no se trata de la naturaleza, sino de lo humano, lo cotidiano, sobrio e intenso. Pájaros cazados, canarios, jilgueros y gorriones con frutas colgando (limones y manzanas), estableciendo una línea diagonal con un enorme cardo. Unas hortalizas se apoyan en el alféizar que constituye la base de un marco geométrico, creando un trompé-l'oeil, tres zanahorias y dos rábanos. Es una obra barroca, uno de los primeros bodegones españoles.

La naturaleza muerta ha sido considerada durante mucho tiempo como un estilo menor, en comparación con el retrato o el paisaje, pero constituye una forma sublime que despliega múltiples significados, como lo es la "literatura menor" de Deleuze cuando analiza a Kafka, o la "ciencia menor" (biología, geografía): "[...] la raza llamada por el arte o la filosofía no es la que se pretende pura, sino una raza oprimida, bastarda, inferior, anárquica, nómada, irremediablemente menor" (1993, p. 111).

Los bodegones, las naturalezas muertas, still life al uso inglés, con sus mínimas diferencias representan un concepto: memento mori. El recuerdo de la fugacidad de la vida, la herida a las vanitas con sus objetos. La ciencia, el arte, los placeres terrenales, todo en estos cuadros se encuentra de una manera fugaz. El pescado queda inmortalizado 
en el instante donde aún no segrega pestilente podredumbre, el limón no dio paso al tono amarronado y a la sequedad que lo convertirá en polvo.

Una muerte y yo un hombre.

Un hombre solo, y ella

una muerte pequeña.

Un hombre, ¿̇y qué? Lo dicho.

Un hombre solo y ella.

Prado, amor, luz y arena.

(García Lorca, 1965/2011)

Memento mori es el recuerdo frente a lo efímero de la vida. La naturaleza muerta en los maestros del arte pictórico nos defiende de las vanitas de nuestra existencia. La finitud de la existencia actúa sobre todo acto soberbio como una atenuación dramática: las flores marchitando, las frutas descompuestas, la podredumbre de la carne, los cráneos expuestos nos igualan en lo que en común tenemos, la conciencia de la propia muerte y lo relativo del poder omnisciente.

La tanatología es el estudio de una naturaleza muerta, estudio de la consecución de un cuerpo hacia lo inorgánico, Génesis 3:19: "acuérdate de que polvo eres y que al polvo volverás". Entre dos muertes, aquella que nos precede y aquella que nos sucederá. La Psicotanatología es el estudio de esa naturaleza humana muerta, aquello que en tanto humano nos permite un resto viviente: el sujeto del lenguaje y el cuerpo viviente (Gadea, Murgia, \& Ortí, 2015).

En febrero de 2017 la Dra. Beatriz Blasco Esquivias de la Universidad Complutense de Madrid dictó la conferencia "La naturaleza inmóvil. Apariencia y Realidad en la pintura de bodegón" (2017) , refiere que en las Conferences de l'academie Royale de Peinture de 1667, André Felibien una clasificación de la pintura poniendo en primer lugar la pintura de historia y en último lugar la pintura de bodegones. En la jerarquización de peldaños se encontraba la superioridad de la naturaleza viva sobre la muerta, seguido en orden ascendiente por el paisaje y sobre ellos aquellos que pintan animales vivos por sobre aquellos que representan cosas sin movimiento. Siguiendo los criterios de la antigüedad, siendo el hombre la representación de dios sobre la tierra, el que pinta la figura humana es más excelente que todos los demás. Sin embargo la cumbre la ocupan aquellos pintores que logran pintar la historia y la fábula, con sus magnas acciones (batallas, pintura sagrada y la mitológica). Este criterio influyó en las academias de Europa. El criterio imperante en Felibien no era la complejidad pictórica en la copia de los objetos, sino el grado de representación del pintor.

Posteriormente el auge de la vida secular y el conocimiento naturista dio un nuevo empuje de las conquistas científicas: la observación pormenorizada de la naturaleza y los cambios físicos que se producían en los objetos, avanzaban en la observación con los cambios de la observación científica. Las nuevas formas de observación con el telescopio y 
el microscopio y el desarrollo de las diferentes ciencias: tanto el macrocosmos como el microcosmos abren paso a nuevas concepciones.

Una nueva era de escala y proporción. La pintura pasa a formar parte de catálogos naturalistas. Reflejo y refracción, especialmente en los florentinos, la maestría de la copia en luz y texturas. Estos cambios dan paso a nuevas formas de luz, color, texturas y proporciones.

Lo descriptivo prima frente a lo narrativo, de tal manera que la naturaleza muerta propone una exposición de los mecanismos físicos intervinientes y el inventariado categorial: categorías de uvas, insectos, mesas prestas al banquete, piezas de cazas. En ellos se observa la maestría de los elementos retratados al mínimo detalle, sus procesos y consecuencias en el transcurrir del tiempo. Pero estas categorías no son excluyentes, así como no es excluyente la descripción teórica y técnica de la pintura, la descripción científica y el simbolismo de las vanitas. Esto es lo que ofrece la riqueza de la naturaleza muerta.

La complejidad de las composiciones considerando la geometría orgánica integrando ideales éticos a la teoría compositiva. La exaltación de la pintura, con su juego de luces y sombras, transparencias, reflejos y refracciones, desafía la maestría de los pintores que deberán poner a prueba su destreza a niveles de los grandes maestros como Rembrandt, Vermeer o Velásquez: "una estética alejada del idealismo e interesada por la apariencia real de las cosas y la forma de representarla" (Vergara, 2019).

\section{Detrás de la pintura}

En una conferencia titulada "Detrás del Cuadro", el Dr. Gabriele Finaldi, Director Adjunto de Conservación e Investigación del Museo del Prado, aborda un tema poco común en el mundo del arte, los reversos de las pinturas, sus estilos y técnicas (2013).

Como conservacionista, el Dr. Finaldi ha tenido acceso a los reversos de numerosas pinturas que ilustraron la conferencia. Detrás de la apariencia que supone la pintura, existe una estructura que marca su devenir, sus misterios, materiales, entramados que hacen de soporte del lienzo y en algunas ocasiones, obras de arte tal y como la que soportan. La conferencia se ilustra con reversos de diversas pinturas pero principalmente de aquellos reversos que no estaban destinados a mostrarse.

Lo interesante resulta de la lectura e interpretación de los materiales, su procedencia, su recorrido, en algunos casos resultan tan determinantes en la constatación de una autoría como la pincelada del pintor. Las marcas, sellos, catalogaciones, etiquetas, antiguas y modernas, que marcan la historia de esa pieza y aportan valiosísima información.

La estructura que soporta aquello que se ve, hace desde su presencia invisible, la esencia de la mirada. Como el derecho y el envés de la trama, soporta un conjunto cuyo recorrido marca de ambos lados el objeto: desde aquello cuyo destino es ser visto y aquello que deberá permanecer oculto. 


\section{Huellas Psicológicas}

La mirada recorre el cuerpo, en todas sus dimensiones, espaciales, históricas, sociales y materiales. El modelo es la autopsia, aútócô廿ıৎ, ver uno mismo. Ver en todas las formas posibles, cortes sincrónicos y diacrónicos, que marcan la complejidad del acontecimiento violento.

La Psicotanatología Forense consiste en aportar al juez todos los indicadores materiales, simbólicos, estructurales, clínicos y semiológicos, que permitan aportar los aspectos psicológicos que intervienen en el acontecimiento violento judicializado.

La naturaleza muerta, interrumpida por la acción violenta, deja marcas. Esas marcas, visibles o rastreables, conforman parte de la estructura del acontecimiento. Así como en la naturaleza muerta en el arte, marca un registro singular, una materialidad concreta y un desarrollo histórico del objeto cuadro, la Psicotanatología Forense se enfoca en hallar las huellas psicológicas que se inscriben en la historia de quienes participan del acontecimiento violento. Iter criminis e iter victimae se encontrarán en el acontecimiento y cada uno dejará una marca evidenciable tanto física como simbólica. Una semiótica del acontecimiento violento, no en el sentido del origen (Ursprung), sino en la construcción de un devenir material.

Los elementos que comprenden la verdad psicojurídica del acontecimiento violento se hallan en el expediente judicial, las operaciones técnicas médicas, criminalística, las declaraciones, lugares y hechos. Con todo esto es necesario ver por uno mismo, entrevistar, ver los lugares, recolectar los relatos e interpretar los resultados.

De la misma manera que una pintura es periciada, buscando tanto los rastros materiales como los simbólicos, los históricos como los físicos; de igual manera la Psicotanatología Forense busca analizar los componentes simbólicos, la historicidad de los sujetos que componen el acontecimiento, el camino que ha llevado a su encuentro y los rastros visibles y aquellos que, por la estructura misma de su naturaleza, resultan invisibles pero determinantes de lo visible.

\section{Aspectos Descriptivos}

Las escenas del crimen son naturalezas muertas. Motivos naturales y objetos, en ocasiones similares al Inventario de Jaques Prévert. Las muertes que ocurren en el ámbito doméstico aparecen congeladas en imágenes: escena cotidiana y ominosa al mismo tiempo, extrañeza inquietante. Lo familiar como extraño (Freud S., 1919/1992).

Lo doméstico se muestra junto a la muerte violenta. El cuerpo, la sangre, la salpicadura, aparece una mirada donde lo cotidiano comienza a medirse en términos de trayectoria, ubicación, distancia precisa. Como la naturaleza muerta, cada uno de los componentes de esa escena es estudiado, analizado y registrado.

La escena ya no es cotidiana, es un conjunto de vectores y medidas, de precisiones y conjeturas. La criminalística traza sus reglas específicas, colecciona, fotografía, recoge 
muestras. El acontecimiento es dividido en numerosas partes que formarán parte de la superficie de registro/control.

Pero dentro de esta escena hay otra, la de aquellos objetos que formaban parte de la vida cotidiana, aquellos que se fueron juntando porque tenían que ver con la vida y lo que le pasaba a ese sujeto antes de morir. Esa vida cotidiana, ese estilo, las relaciones, lo vital dentro de la muerte, es lo que forma el núcleo de análisis de la tanatología forense.

\section{Conclusiones}

La autopsia psicológica es un dispositivo de la psicotanatología forense que se ocupa de los aspectos psicológicos de una persona fallecida y su relación con la muerte. Se trata de una reconstrucción post-mortem, una reconstrucción retrospectiva mediante el conjunto heterogéneo de indicadores que permiten correlacionar las huellas psicológicas con el acontecimiento-muerte.

La escena y la disposición de los cuerpos marcan el inicio del trabajo de reconstrucción, un après-coup que resignifica el acontecimiento en función del hallazgo de las huellas psicológicas. Como se ha mencionado, casa escena tiene una composición, un ordenamiento particular de los objetos. Detrás de esa composición hay una historia que surge de la heterogeneidad de elementos, disposición discontinua de elementos inicial, pero que el minucioso análisis de la información va estableciendo en términos de continuidades: comienza a delinearse la historia de un sujeto. No se trata de una crónica al modo de historia policial, se trata de una lógica detrás de los aspectos psicotanatológios.

Los relatos reeditan las palabras de los muertos, describen su mundo simbólico, sus relaciones, pero también los reversos de las tramas, los silencios, las omisiones. La escucha analítica es el marco de la entrevistas clínico forenses, porque es la que permite objetivar la dimensión real del acontecimiento-muerte. Las descripciones y la información de los expedientes van formando fenómenos aleatorios parcialmente dependientes, que recuerdan a las cadenas de Markov (Deleuze \& Guattari, 1972/2007, p. 265), estableciendo una escritura que aúna los registros sobre la muerte y la violencia.

El proceso de autopsia psicológica acompaña la degradación del cuerpo, de la escena, de la historia, pero rescata el registro de esa singularidad, la del acontecimientomuerte y su vínculo con la subjetividad de la víctima. Como la naturaleza muerta, retrata el acontecimiento vital, aquello que todavía se encuentra allí, en ese acontecimiento, del que queda el registro desde el nacimiento hasta la muerte. Still life.

\section{Referencias bibliográficas}

BLASCO ESQUIVIAS, B. (15 de febrero de 2017). La naturaleza inmóvil. Apariencia y realidad en la pintura de bodegón. Madrid, España: Museo Nacional del Prado.

DELEUZE, G. (1970). Lógica del sentido. Barcelona: Barral. 
DELEUZE, G. \& GUATTARI, F. (1972/2007). El Antiedipo, Capitalismo y Esquizofrenia. Barcelona: Editorial Paidos.

DELEUZE, G. \& GUATTARI, F. (1993). ¿Qué es la filosofía? Barcelona: Anagrama.

FINALDI, G. (20 de noviembre de 2013). Conferencia: Detrás del Cuadro. Los reversos del Museo del Prado. Madrid, España: Museo del Prado.

FREUD, S. (1919/1992). Lo ominoso, Obras completas, (Vol. XVII). Buenos Aires: Amorrortu Editores.

FREUD, S. (1920/1992). Más allá del principio del placer (Vol. XVIII). Buenos Aires. Amorrortu editores.

FREUD, S. (1938/1976). Esquema del psicoanálisis (Vol. XXIII). Buenos Aires: Amorrortu Editores.

GADEA, L., MURGIA, A., \& ORTí, M. (2015). Lenguaje, pulsión y ética del psicoanálisis. VII Congreso Internacional de Investigación y práctica profesional en psicología (p. 276, 279). Buenos Aires: Acta Académica.

GARCÍA LORCA, F. (1965/2011). Federico García Lorca - Poesía Completa. España: Galaxia Gutemberg.

HOEZEN POLACK, B. (2002). Lacan y el Otro. A parte rei: Revista de Filosofía №21, p. 9. Obtenido de Instituto Nacional de Tecnologías Educativas y de Formación del Profesorado.

MARCH, J., CASSELL'S. (1999). Dictionary Of Classical Mythology, Londres.

RICARDO, D. (2018). Autopsia Psicológica. Psicotanatología Forense. Buenos Aires: Tercero en Discordia.

SIMONDON, G. (2015). La individuación a la luz de las nociones de forma y de información. Buenos Aires: Cactus.

TULA MOLINA, F. (Junio de 2014). Simondon: La individuación. (Editorial Universidad de Quilmes) Redes, Vol. 20, №38, p. 199 - 208.

VERGARA, A. (25 de junio de 2019). Museo del Prado. Exposición Velázquez, Rembrandt, Vermeer. Miradas afines. Madrid, España. Obtenido de Museo del Prado.

* Damián G. Ricardo: Perito Oficial en el Cuerpo Pericial de Psicología Dependiente del Poder Judicial de la Provincia de Santa Cruz. Magister en Metodología de Investigación en Ciencias Sociales (UNPA). Licenciado en Psicología (UBA). Miembro del ICIC-UNPA. [E-mail: damianriardo@hotmail.com] 